I sommeren 1991 udkom A Shakespeare Music Catalogue. Oxford, Clarendon Press. 5 vols., hvis tilblivelse den nordiske bidragyder, musikbibliografen Nanna Schiødt redegjorde for i Magasin, 4. årg. nr. 2, 1989. I fortsættelse heraf giver hun her nogle indtryk af, hvad man kan få ud af dette storværk.

\title{
Musik og Shakespeare
}

af cand.mag. Nanna Schiødt

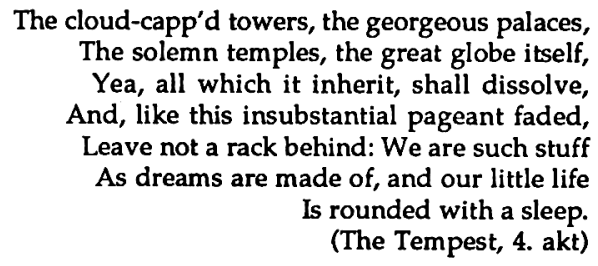

A Shakespeare Music Catalogue udkom i 5 bind i sommeren 1991.

I Magasin 1989 beskrev jeg mit arbejde med at finde det skandinaviske stof til katalogen rundt omkring i de nordiske lande. Hvad mon der er fundet andre steder i verden fra Shakespeares tid og til 1988? Hvad mon katalogen som helhed kan fortælle?

Som medarbejder kan jeg huske, at jeg i starten undrede mig over de mange detaljer af ikke-musikalsk relevans, der skulle inkluderes i registreringen. Nu kan man se, at disse har givet en kulturhistorisk synsvinkel til den Shakespeare-relaterede musik, uden hvilken værket ville have været kedeligt.

Der er utroligt mange facetter i katalogen, ikke blot udtrykt i de mange indekser, der åbner dørene, men også når man nærlæser de enkelte indgange, af hvilke der er $21362 \mathrm{i}$ musikkatalogen og $3232 \mathrm{i}$ bibliografien. Komponister, skuespillere, førsteopførelser, instruktører, koreografer, dirigenter, og oversættere er med overalt, og det er de mest forunderlige oplysninger, man støder på. 


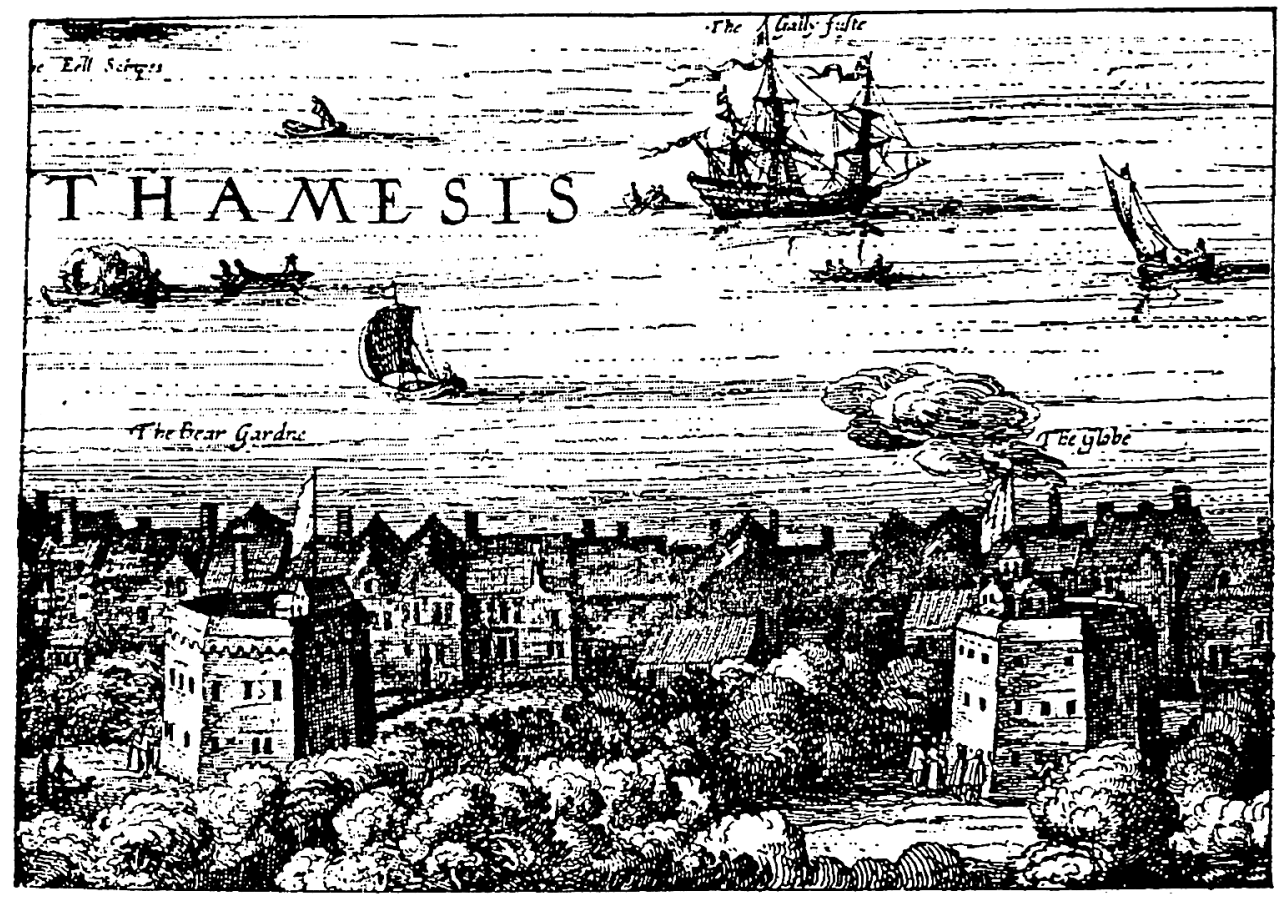

Globe teatret, som man nu er ved at rekonstruere pa samme sted, hvor Shakespeares The Globe i sin tid lå.

\section{Antal opsætninger med musik. Alle Shakespeares skuespil}

Det kunne være interessant at se, hvor ofte der har været sat musik til Shakespeares 43 skuespil, når de har været opført på scene, film, radio og TV.

I katalogen er der foran hvert eneste skuespil angivet, hvor Shakespeare selv ønskede musik, men det er ikke ensbetydende med, at det er blevet fulgt til punkt og prikke af instruktører og komponister. Rækkefølgen, som ses nedenfor, undrer nok ikke. De stykker, man bedst kender, har også hyppigst været i hænderne på en komponist. Eller er det måske, fordi de har været ledsaget af musik, at man kender dem bedst?

$$
\begin{aligned}
\text { Antal indgange } & \text { Shakespeares titel } \\
1763 & \text { Twelfth night or What you will } \\
1724 & \text { A midsummer night's dream } \\
1632 & \text { As you like it }
\end{aligned}
$$




\begin{tabular}{|c|c|}
\hline 1608 & The tempest \\
\hline 1406 & The tragedy of Hamlet, Prince of Denmark \\
\hline 1130 & The tragedy of Romeo and Juliet \\
\hline 895 & The tragedy of Macbeth \\
\hline 886 & The tragedy of Othello, the Moor of Venice \\
\hline 750 & The merchant of Venice \\
\hline 663 & Much ado about nothing \\
\hline 537 & The tragedy of King Lear \\
\hline 501 & Love's Labour's Lost \\
\hline 491 & The winter's tale \\
\hline 475 & The taming of the shrew \\
\hline 468 & The merry wives of Windsor \\
\hline 460 & Measure for Measure \\
\hline 454 & Cymbeline \\
\hline 323 & The tragedy of Julius Caesar \\
\hline 319 & The two gentlemen of Verona \\
\hline 309 & The tragedy of Richard the Third \\
\hline 280 & The tragedy of Antony and Cleopatra \\
\hline 279 & The famous history of the life of Henry the Eighth \\
\hline 247 & The comedy of errors \\
\hline 229 & The first part of Henry the Fourth \\
\hline 169 & The second part of Henry the Fourth \\
\hline 167 & The tragedy of Coriolanus \\
\hline 166 & The passionate pilgrim \\
\hline 165 & The tragedy of King Richard the Second \\
\hline 154 & The life of Henry the Fifth \\
\hline 153 & The history of Troilus and Cressida \\
\hline 106 & All's well that ends well \\
\hline 90 & The life of Timon of Athens \\
\hline 86 & The life and death of King John \\
\hline 72 & Pericles, Prince of Tyre \\
\hline 44 & The second part of Henry the Sixth \\
\hline 43. & The tragedy of Titus Andronicus \\
\hline 41 & The first part of Henry the Sixth \\
\hline 38 & Venus and Adonis \\
\hline 37 & The third part of Henry the Sixth \\
\hline 17 & The two noble kinsmen \\
\hline 15 & The Phoenix and Turtle \\
\hline 14 & The rape of Lucrece \\
\hline 2 & A lover's complaint \\
\hline
\end{tabular}

De 154 sonetter er sat i musik 1408 gange. Favorit-sonetterne er "Shall I compare thee to a summer's day" (no.18) og "Music to hear" (no.8). Danske komponister har sat musik til dem begge samt til flere andre sonetter. Richard Simpson, en engelsk komponist der døde i 1876, har sat musik til alle 154 sonetter, nogle af dem flere gange. 


\section{Antal opsætninger af Helligtrekongers aften}

Man kan også kigge på, hvor mange gange skuespillene er blevet opsat i de forskellige lande, med musik, vel at mærke, da de jo også er opført mange gange uden musik.

Jeg har valgt Helligtrekongers aften. Her kommer USA ind som nummer ét med 150 opsætninger. Det skyldes vel det engelske sprog og det store land.

Derefter kommer Tyskland med 137 opførelser. Der har altid været en stor Shakespearetradition i Tyskland. Danske forfattere rejste til Tyskland omkring 1800 og oplevede Shakespeare ved at se stykkerne og i det litterære samvær med deres tyske kolleger. - Danmark importerede tyske teaterkompagnier i slutningen af 1700-tallet, som hos de adelige familier på Fyn opførte Shakespeare på tysk. Det siges også, at englænderne først rigtigt forstod flere af Shakespeares stykker, da tyskerne havde oversat (udlagt) dem.

Derefter kommer England med 101 opførelser, USSR 32, Tjekkoslovakiet 25, Polen 25, Schweiz 17, Østrig 17, Australien 15, Canada 14, Sverige 13, Frankrig 10, Jugoslavien 10, Danmark 9, Skotland 8, Italien 7, Ungarn 5, Belgien 5, Rumænien 4, Holland 4, Japan 4, Finland 3, New Zealand 3, Bulgarien, Norge, Kina og Litauen 2, Island, Irland, Filippinerne, Uruguay og Argentina 1.

Disse tal kan give en mistanke om, at der ikke alle steder har været lige stor velvillighed til at besvare Shakespeare-centrets spørgeskemaer, og i de tilfælde, hvor centrets medarbejdere har været på stedet, er der fundet mere materiale, end hvor man har måttet basere efterforskningen på korrespondance.

\section{Antal opsætninger med musik for 3 af skuespillene}

Hvis man prøver at se på antallet af opførelser gennem de 400 år, er der kun få tvivlsomme overleveringer af musik fra den allerførste tid. Man diskuterer, om Thomas Morley og Robert Johnson har sat musik til Shakespeares stykker, eller om Shakespeare har valgt deres allerede komponerede musik.

Det har iøvrigt undret mig og generer mig stadig, at den første opførelse af Shakespeare herhjemme først er i 1811, da Claus Schall og Galeotti sætter balletten Romeo og Giulietta op på Det kgl. Teater. Hvorfor var kong Christian IV ikke i forbindelse med Shakespeares skuespiltrup under 
sine Englandsbesøg og inviterede dem til København under de mange festligheder, han holdt? Måske var det mest musik, der interesserede ham, og måske var der ikke mange, der forstod engelsk i København? Jeg har i hvert fald endnu ikke kunnet finde så tidlige spor af Shakespeare herhjemme.

I slutningen af 1600-tallet blev Henry Purcells musik brugt ved opførelser af Shakespeare, men han komponerede ikke direkte til nogen af stykkerne.

I 1700-tallet begyndte Shakespeare endelig at blive kendt på fastlandet, hvor bl.a. Bach-sønnerne, Dittersdorf, Haydn og Salieri komponerede Shakespeare-musik.

I 1800-tallet tog romantikerne fat, og i vort eget århundrede er opførelser med musik blevet mere og mere hyppige, ligesom de har spredt sig fra scenen til alle medier og genrer.

Jeg har valgt at se på 3 skuespil for at undersøge antallet af opsætninger gennem tiderne: Hamlet, Romeo and Juliet og Timon of Athens:

\begin{tabular}{|crrrrrrr}
\hline Tidsrum & \multicolumn{2}{c}{ Hamlet } & & \multicolumn{2}{c}{ Romeo } & & \multicolumn{1}{c|}{ Timon } \\
-1699 & & $\%$ & & $\%$ & & $\%$ \\
$1700-99$ & 6 & 1,1 & 5 & 1,2 & 2 & 7,7 \\
$1800-99$ & 34 & 6,0 & 21 & 5,0 & 2 & 3,8 \\
$1900-19$ & 21 & 3,7 & 8 & 1,9 & 2 & 3,8 \\
$1920-29$ & 20 & 3,5 & 15 & 3,6 & 2 & 3,8 \\
$1930-39$ & 23 & 4,1 & 20 & 4,8 & 4 & 7,7 \\
$1940-49$ & 44 & 7,8 & 28 & 6,7 & 3 & 5,8 \\
$1950-59$ & 82 & 14,5 & 67 & 16,0 & 3 & 5,8 \\
$1960-69$ & 110 & 19,4 & 78 & 18,6 & 11 & 21 \\
$1970-79$ & 129 & 22,8 & 81 & 19,3 & 11 & 21 \\
$1980-89$ & 98 & 17,3 & 96 & 22,9 & 8 & 15,4 \\
Ialt & 567 & & 419 & & 52 & \\
\hline
\end{tabular}

"Timon of Athens, the Man-Hater", var den første af de 3, der blev opført, men har ikke siden tiltrukket mange. Romeo har tiltrukket flere og flere, mens Hamlet er gået lidt tilbage i 80-erne.

\section{Komponister}

I katalogen er der næsten lige så mange komponister, som der er kompositioner. Der er f. eks. 415 forskellige komponister til de 469 scenemusik-kom- 
13372 Olivier, Laurence. [-]. MS [I940]. Incidental music. First performed [Geary Theatre], San Francisco, 8 April I940 (see 13479 for further details). The programme for this production states that the 'Original music [was composed] by Mr. Steinert and Mr. Olivier'. According to a letter of Vivien Leigh, quoted by Felix Barker in The Oliviers (London: Hamish Hamilton, r953), p. I67, Olivier composed 'his own entrance music for Romeo. Now he's going to compose mine for Juliet'.

Laurence Olivier og Vivien Leigh mødtes på Kronborg som Hamlet og Ophelia lige før 2. verdenskrig og blev forelskede i hinanden. I dette eksempel fra $A$ Shakespeare Music Catalogue ses det, at de bl.a. senere optrådte som Romeo og Julie.

positioner til Romeo og Julie, og det er ikke mange af dem, man kan finde $\mathbf{i}$ almindelige musikleksika. I hvert fald ikke Laurence Olivier, der engang komponerede musikken til sig selv og Vivian Leigh som Romeo og Julie.

Det har ikke altid været morsomt for kendte komponister at skulle underordne sig så stærk en tekst som et Shakespeare-skuespil. Så blev der jo ikke lagt så meget mærke til deres musik. Måske er det derfor, at så mange mindre kendte personer har afprøvet deres talenter i skuespilmusikken. Mendelssohns musik til En Skærsommernatsdrøm er den eneste, der virkelig er blevet stående, ligesom vi herhjemme stadig har Rungs og Heises dejlige sange. Jeg kan også nævne anmeldelsen af Macbeth, der blev opført på Det kgl. Teater i 1817, som priser Weyses musik, "uden hvilken Macbeth ville have været alt for uhyggelig".

Ud af både bibliografien og katalogen kan man læse, hvor optaget komponisterne har været af Shakespeare. Ikke alene har de ladet sig inspirere til at skrive færdige kompositioner, helst ikke underlagt selve skuespillet, men flere af dem har i årevis drømt om at komponere selvstændig musik, operaer el. lign. inspireret af et af hans skuespil, men har måttet opgive og er ikke nået længere end til udkast, evt. et par sange eller en ouverture.

Det kendteste eksempel er Verdi (1813-1901), der gennemførte Macbeth (1847) Otello (1887) og Falstaff (1893), men opgav Kong Lear, fordi scenen på heden var for stærk, og ligeledes opgav Hamlet, fordi "this masterpiece of English theatre" forekom ham endnu sværere at gengive i musik. Romeo og Julie fik Verdi komponeret første akt af, men han følte sig for gammel (i 1890 da han var 77 år) til at kunne gøre den færdig. Falstaff, et af hans mesterværker, har åbenbart passet bedre til hans gemyt. Den komponerede han, da han var 80.

Også Tjajkovskij prøvede på at skrive en opera over Romeo og Julie i 20 år, men det lykkedes ikke. 
Svenskeren Kurt Atterberg (1887-1974) bearbejdede Stormen gennem et helt liv. Han begyndte med scenemusik i 1921, omarbejdede og brugte den flere gange ved opsætninger i de følgende årtier. I 1948 komponerede han den som opera, og flere gange, helt op til 1965, fortsatte han med at komponere suiter baseret på sit allerede foreliggende materiale. Mendelssohn opgav kampen med Stormen.

Richard Wagner gjorde to forsøg på at lave en opera med Shakespeare-emne. Mozart fik en libretto til Stormen i oktober 1791, som han døde i december. Librettoen blev derefter givet til Dittersdorf, men han ville lave for mange ændringer $\mathrm{i}$ teksten, så operaen endte med at blive komponeret af Friedrich Fleischmann ca. 1796.

Alle, der arbejder med kataloger og bibliografier, hảber på at få det hele med. Som regel lykkes det ikke. For eksempel er denne sang ikke kommet med i katalogen. PH skrev den til Dagmarrevyen i 1941 inspireret af de sidste ord i denne artikels indledende Shakespeare-citat. Kai Normann Andersen har komponeret musikken.
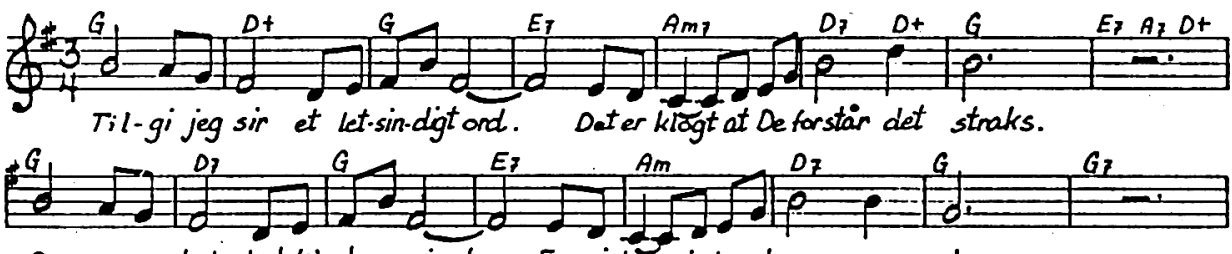

Ba-re en hyl-dest til den-ne jord. For vi hä jokunden sam-me slags.

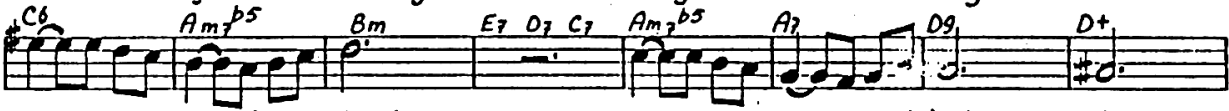

Ver.den har nue ha-det mer end nok. Vi kan kun be-sua-re medat el - ske.

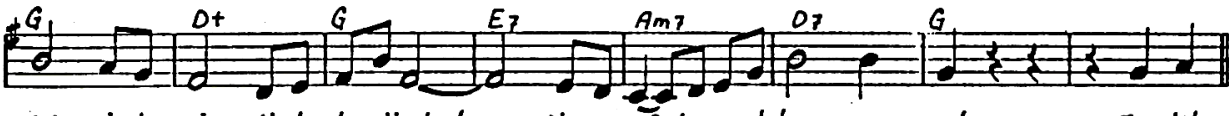

Selu iden jor-di-ste ker.lig-hed lig-ger vä-ben modet nag-na-rok. I dit

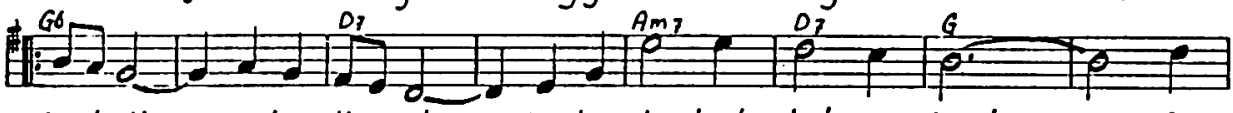

kor-te liv erhuer ti-me dyr huert se-kund, et dyrt se-kund. Du
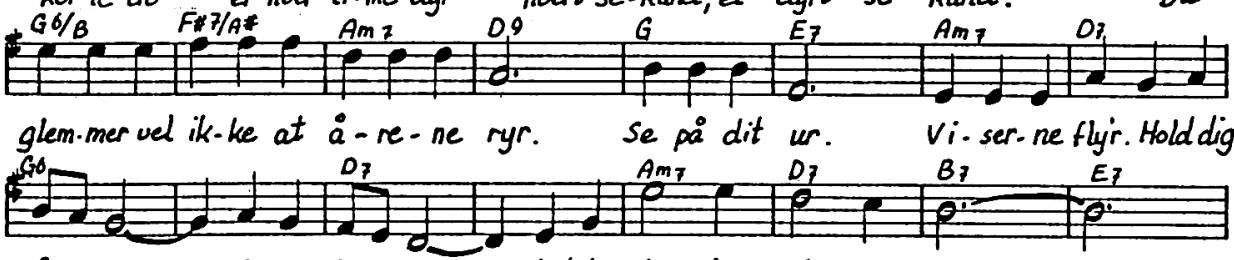

va-gen ven. Vo-res lil.le liv slut-tes in - de af en squn.

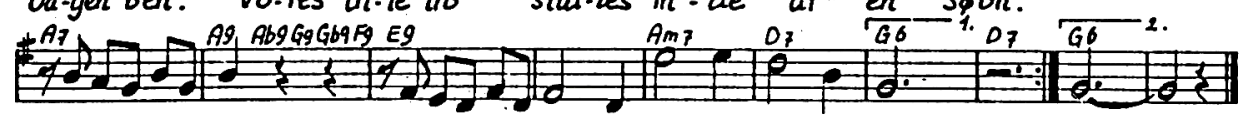

Vier af sam-me stof, som drom.me $g \phi$-res af, det sto-re tom-me rum. soun. 


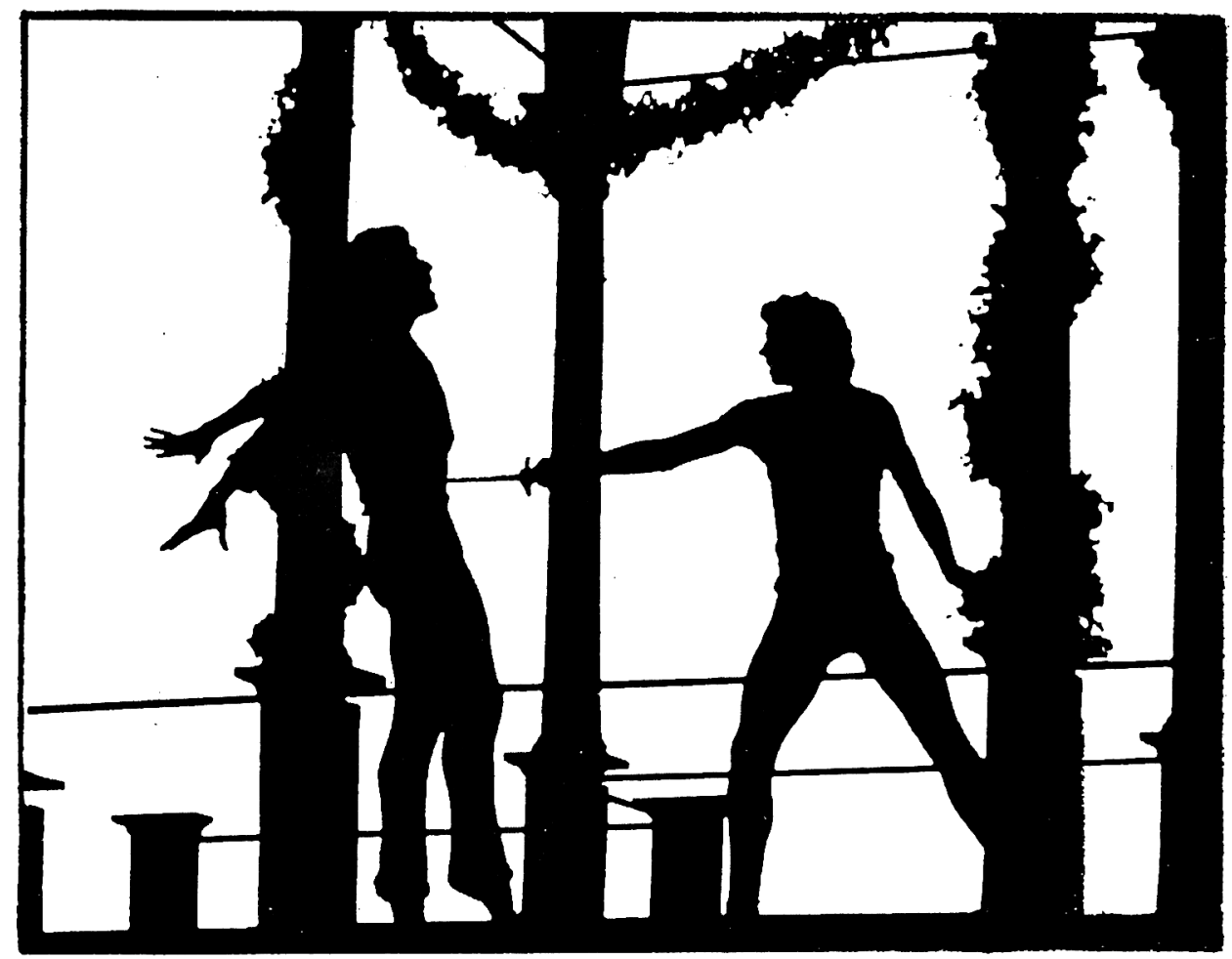

Utallige er de koreografer, der har omsat Shakespeares ord til bevægelse. Den første herhjemme var Galeotti, i 1811. Komponisten Claus Schalls kone dansede Julie, og Bournonvilles far, Antoine, var Romeo. Dette billede er fra John Neumeiers version 1971 til Prokofieffs musik, opført i København i 1974.

Schumann skrev i adskillige breve begejstret om sine planer for en Romeo-opera, uden at det nogensinde blev til noget, og Stravinskij havde skitser til Love's Labour's Lost, men det løb ud i sandet. I 1975 var der stærke rygter om, at Elton John planlagde en rock-opera med David Bowie som Ophelia, men det blev ved rygterne.

Shakespeares tekster er måske for stærke? Ofte synes jeg, de bedst udtrykkes i balletter, som der er mange af i katalogen, men tit, som i tilfældet Neumeier, er musikken valgt af koreografen fra allerede eksisterende kompositioner og ikke komponeret til balletten, så de er ikke med i katalogen.

For at bevare deres musik for eftertiden har komponisterne i mange tilfælde skabt orkestersuiter eller klaverstykker af "døgnfluemusikken", som man godt kan kalde skuespilmusikken. Derved opnår de, at deres musik spilles ved koncertopførelser og evt. indspilles på plade og derved bliver mere udødelig. Måske bliver musikken ovenikøbet trykt. Det blev de bedste sange af Rung og Heise, når de havde været opført med succes på Det kgl. Teater. 
Orkesterstykker blev siden i mange tilfælde brugt som grundlag for koreografi til Shakespeare-balletter. Det gælder f. eks. Tjajkovskijs ouverture til Romeo og Julie (længere nåede han som ovenfor anført ikke), skrevet 1869 og brugt 14 gange til balletter, bl.a. af Birger Bartholin (Paris 1937) og Poul Gnatt (New Zealand 1955).

Selv om Shakespeare i flere af skuespillene kun har anført få musikangivelser, har stykkerne alligevel inspireret mange til at komponere musik i alle genrer. - Nogle kompositioner er inspireret af scener i skuespillene, andre af enkeltpersoners karakterer (Caliban, Ariel, Ophelia), andre igen af replikker. Dette gælder f.eks. Ture Rangströms Improvisationer for klaver over "We are such stuff as dreams are made on" fra 4. akt i Stormen. Den replik har også inspireret Vaughan Williams i sidstesatsen af hans 6 . symfoni. - Tit sættes Shakespeare-citater over enkeltsatser eller foran hele kompositioner.

For mange komponister har inspirationen efter læsning af Shakespeare været mere almen, og er stadig genstand for diskussion, hvad man kan se i bibliografien. Beethoven skulle således have været inspireret af Stormen i Appasionata og af sidste scene i Romeo og Julie i sin strygekvartet op. 18,1.

En mand med det dristige navn William Shakespeare, blev så optændt af at se Ernesto Rossi spille Hamlet, at han gik hjem og komponerede en ouverture for lutter blæsere i 1874. Den blev dog først opført i 1902 i London med komponisten selv som dirigent.

\section{Genrernes skiften gennem tiderne}

Jeg har omtalt romantikken, hvor man ofte skar i eller tildigtede eller lavede om på Shakespeares tekst: Den var lidt for uhyggelig og for uartig for den tids mennesker, inclusive komponisterne.

I 1930'erne og 40'erne tog jazzmusikerne fat på Shakespeare. I New York satte James Van Heusen En skærsommernatsdrøm op som 'Swingin' the Dream" , hvor både Louis Armstrong og Benny Goodman's sextet med Fletcher Henderson og Lionel Hampton og et Jitterbug chorus deltog. Ligeledes komponerede Duke Ellington flere ting inspireret af Shakespeare.

Rock-operaer og musicals kom i store mængder i 60-erne og 70-erne, f. eks. Bernsteins "West Side Story" (Romeo og Julie), Cole Porters "Kiss me Kate" (Trold kan tæmmes) og Rock-operaen "Kronberg:1582" (Hamlet) fra 1972, der i New York 1976 skiftede navn til "Rockabye Hamlet" og endelig i Los Angeles versionen i 1981 blev kaldt "Somethin's Rockin' in Denmark". 
966 Schering, Arnold. Beethoven in neuer Deutung I. Die Shakespeare-Streichquartette, Op. 74, Op. 95, Op. 127, Op. 130, Op. 131. Die Shakespeare-Klaviersonaten, Op. 27 Nr. I, Op. 27 Nr. 2, Op. 28, Op. 3 I Nr.1, Op. 31 Nr. 2, Op. 54, Op. 57, Op. 1 II. Die SchillerKlaviersonate, Op. 106. Leipzig: C. F. Kahnt, I934, I 8 pp.

Claims Beethoven composed five string quartets and eight piano sonatas with these plays in mind: Hamlet, Henry VIll, Lear, Macbeth, Merchant, Merry Wives, Dream, Much Ado, Othello, Romeo, Shrew, Tempest, and Winter's Tale. For objections to Schering's claims see 949 and 958.

Review : R. Steglich, Zeitschrift für Musik IOI (Nov. 1934): I094.

967 Schering, Arnold. Beethoven und die Dichtung: Mit einer Einleitung zur Geschichte und Asthetik der Beethovendeutung. Hildesheim: Georg Olm, I973, 620 pp.

Links Beethoven and $S$, passim. \{Ist edn., 1936.\} For objections to Schering's claims see 949 and 958.

Utroligt hvad Shakespeare efter nogens mening har inspireret til. Her har Arnold Schering ment at kunne påvise inspirationen i en række af Beethovens kompositioner. Pástandene blev selvfølgelig imødegået og diskuteret, hvilket man også kan se i bibliografi-bindet.

949 Blom, Eric. Beethoven's Pianoforte Sonatas Discussed. New York: Da Capo Press, I 968, viii + 25I pp.

Doubts Arnold Schering's claim (see 966 and 967) that string quartets and piano sonatas were inspired by $S$ 's plays, pp. 31-313. \{227st edn., 702.\}

958 MacArdle, Donald. 'Shakespeare and Beethoven'. Musical Times ro5 (April I964): 260-26I.

Composer's knowledge of $S$. Author doubts Arnold Schering's claim (see 966 and 967) that string quartets and piano sonatas were inspired by $S$ 's plays. Victor Standing, in a letter to editor of Musical Times I05 (June 1964): 439, suggests a connection between $S$ 's last plays and Beethoven's late quartets.

Danse af alle arter har også været komponeret over navne og citater fra Shakespeare. Det begyndte allerede sent i 1800-tallet. Meget pudsigt er forfatteren til en anmeldelse af Shakespeare-katalogen i Times Literary Supplement, august 1991, blandt de over 20,000 indgange i katalogen faldet over vor egen Leo Mathiesens foxtrot "To be or not to be" fra 1943, som blev brugt som omslag på Det kongelige Biblioteks Magasin i 1989. Overskriften til Brian Vickers' anmeldelse er iøvrigt "Something rocking in Denmark".

\section{Bibliografien}

I litteraturbindet om Shakespeare og musik er der mange spændende og ejendommelige ting at læse. Skribenter har sammenlignet Hamlet med 
Don Juan, Tryllefløjten med Stormen, Wagners Tristan og Isolde med Romeo og Julie. De har beskrevet indflydelsen af Beethovens Shakespearelæsning på hans klaversonater og strygekvartetter.

En mængde litteratur er der selvfølgelig om Verdi og hans Shakespeare-operaer.

Claus Schall, hvis balletmanuskripter findes på Det kongelige Bibliotek, ses $i$ bibliografien at være behandlet $i$ en tysk disputats fra 1930 af Julius Friedrich. Den er trykt i Berlin. I det hele taget kaster bibliografien meget lys over katalogen.

Både katalog og bibliografi er velforsynede med indexer. Der er f. eks. et med ca. 1000 musikforlag fra hele verden. Et med titler og førstelinier af sange på alle sprog. Et med komponister, arrangører og udgivere, samt et med biblioteker og institutioner med Shakespearemateriale.

Katalogen medtager også, hvad der ligger i periferien af, hvad man ville godtage som inspireret af Shakespeare.

Der er desuden et afsnit om kompositioner, som man $i$ arbejdet med denne katalog har bevist absolut ikke har noget at gøre med den store forfatter.

Der er åbenbart ingen grænser for, hvad Shakespeare kan bruges til. I Hamlet-afsnittet under indgang 3907 fandt jeg: Busch, Siegfried: Tuba or not Tuba. Composition for solo jazz tuba. 1973. Det tog mig lidt tid at finde ud af, hvad den titel bestilte dér.

Dette var blot en lille mundsmag på, hvor spændende det er at gå på opdagelse i "A Shakespeare Music Catalogue". Den er iøvrigt blevet forslået af Anthony Burgess til the Observer og er antaget som en af deres "Books of the Year".

Bryan N.S.Gooch and David Thatcher: A Shakespeare Music Catalogue.

Vol.1: The catalogue of music: "All's well that ends well" - "Love's Labour's Lost". 703 s. 70 £. 0198129416

Vol.2: "Macbeth" - The Taming of the Shrew" 798 s. $70 £ 0198129424$.

vol.3: "The tempest" - "The two noble kinsmen", The sonnets, The poems, Commemorative pieces, Anthologies. 681 s. 60 £. 0198129432

Vol.4: Indices. 350 s. 60 £. 0198129440

Vol.5: Bibliography. 308 s. $40 £ .0198129459$

Oxford: Clarendon Press. 